\title{
Mis programas favoritos 2
}

\author{
EDUARDO COSOI P. ${ }^{1}$ \\ 1. Profesor Asistente. Universidad de Chile. Unidad Lactante y Nutrición, Hospital Luis Calvo Mackenna.
}

Hay una serie de programas y utilidades que conviene conocer y saber utilizar.

Uno de mis favoritos es Pando. Con seguridad ha tenido que enviar archivos adjuntos a través de e-mail. La mayoría de las casillas tiene un tope de hasta $10 \mathrm{MB}$ para este tipo de archivos (no tiene nada que ver con la capacidad de la casilla) Gmail tiene casi 3 GB de capacidad, pero limita el envío a los mismos 10 MB. Por otra parte, si se desea enviar algunos tipos de archivos como programas -.exe-; algunos archivos comprimidos -zip o rar-, etc la mayoría de los proveedores de servicio también los restringen por temor a que sean portadores de virus.

Para esto está Pando (www.pando.com). Permite el envío de todo tipo de archivos de hasta 1 GB de tamaño vía e-mail, incluso se pueden mandar carpetas completas. Al descargar el programa, que es relativamente pequeño, existe un mínimo proceso de inscripción, en que básicamente hay que señalar la dirección de correo electrónico y queda listo para ser utilizado. Simplemente se explora el disco duro y se colocan los archivos o carpetas completas que se desean enviar. El sistema funciona descargando el archivo adjunto en los servidores de Pando, quienes en forma instantánea envían un email al o los destinatarios que se han señalado en la interfaz de Pando, indicándoles que se les está enviando un archivo adjunto y que para descargarlo necesita tener Pando en su computador. Al descargarlo, el destinatario en forma inmediata comienza a descargar lo enviado. Al mismo tiempo, el destinatario puede empezar a descargar el archivo. Otra de las ventajas es que si se quiere pausar la descarga, lo puede hacer sin necesidad de que tenga que partir desde cero. Funciona en MAC o PC. Es ideal para enviar fotografías o compartir videos. Para este tamaño de archivos el sistema es gratuito. Existe la posibilidad de comprar una subscripción que da derecho de mandar archivos de hasta 5GB de tamaño a más de 100 usuarios simultáneamente. Simplemente se busca en el Explorer (PC) o Finder (MAC) los archivos o carpetas que se desean enviar y se colocan encima de la interfaz de Pando (figura 1 y 2).

Otro de los programas que considero interesante es Itunes (http://www.apple.com/es/itunes/ download/). Aunque su utilidad máxima es para la sincronización con los Ipod y otros equipos de música, permite ordenar y clasificar toda la música que está disponible en el computador. Otra de sus funciones que considero relevante es que tiene una base de datos en línea de muchas radios que transmiten a través de Internet. Están clasificadas en música clásica, contemporánea, jazz, noticias, etc. La calidad de la recepción y sonido es excelente, mejor que con otros reproductores disponibles. Tiene estaciones de muchas partes del mundo y han sido seleccionadas por ser las mejores. Ideal para escuchar música mientras se trabaja. Está disponible para PC y Mac.

Otro de mis programas favoritos es Mozilla Firefox, disponible tanto para Mac como para PC (www.mozilla.com). Es un explorador de 
Internet alternativo de Microsoft, que tiene la gran ventaja de que tiene menos probabilidad de encontrar virus que se transmitan a través del Explorer de Microsoft. Funciona con el sistema de "'pestañas" que permiten mantener disponible varias ventanas en el interior de solo una de ellas al cual se

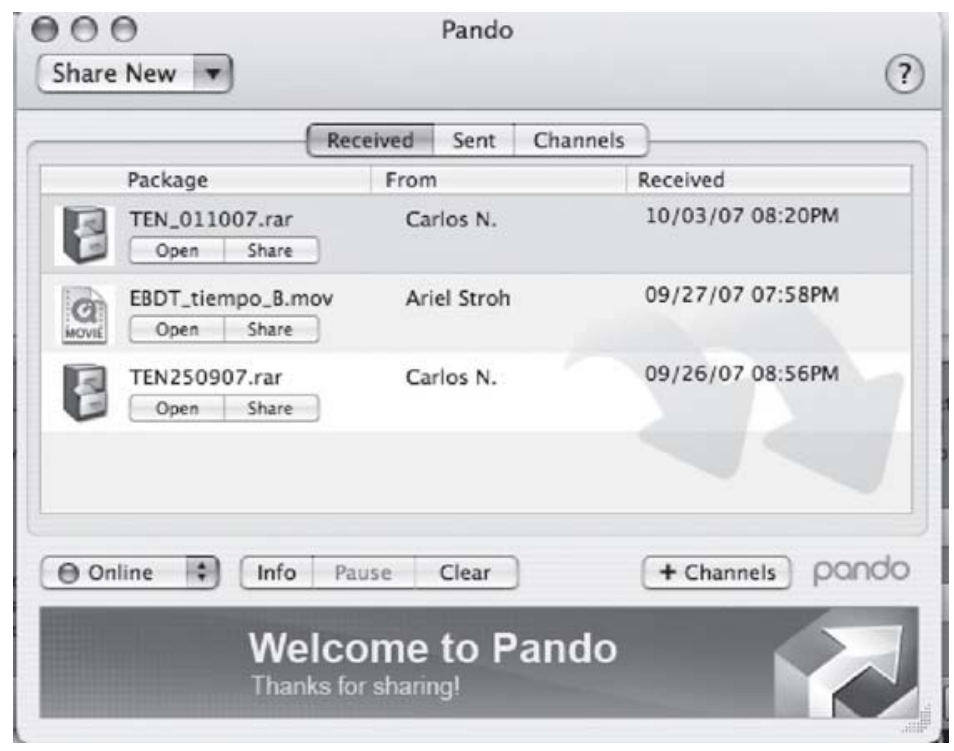

Figura 1.

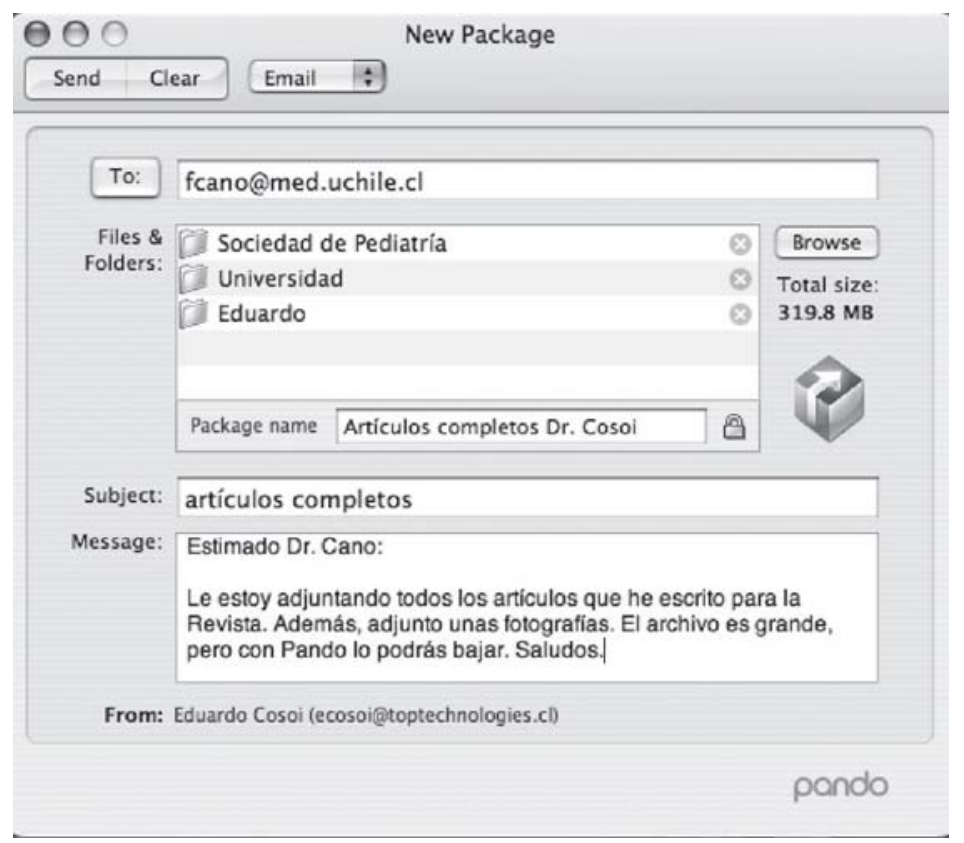

Figura 2. acceden haciendo clic sobre la pestaña. Tiene un sistema de búsqueda más avanzado que Explorer, ya que marca en color la palabra que se busca. Tiene además la gran ventaja de que a los usuarios de Mac les permite acceder a una serie de páginas que se encuentran limitadas con el explorador de Mac, Safari, ya que fueron diseñadas para el Explorer. Aunque esto último no es $100 \%$, resuelve una buena parte del acceso especialmente a páginas Web de bancos. Otro de los exploradores recomendables es Safari. No hay que dejar de mencionar que los usuarios de PC pueden acceder a las ventajas del explorador de Mac, Safari (www.safari.com). Este explorador, al igual que Firefox, tiene la ventaja de que no tiene, aún, problemas significativos de seguridad y su interfaz es lógica y entretenida (figura 3).

Otro de los programas que considero de interés es "Logme In” (www.logmein.com). Consiste en un sistema que permite manejar un PC o Mac en forma remota. Es especialmente útil cuando se desea acceder a un computador que se encuentra físicamente separado en el cual se desean realizar modificaciones, enviar o compartir archivos. La situación típica es que se tiene un PC estacionario, donde se encuentran todos los emails y que tiene una gran capacidad de almacenamiento. Uno se encuentra de viaje con el notebook y se olvidó de traer una presentación. Con Logme In es extremadamente fácil. Se descarga desde la página Web, se siguen las instrucciones y muy rápidamente, en forma gratuita, se puede acceder al PC de la 
casa. Esto incluye la pantalla, el Mouse, teclado, etc. La versión pagada de Logme In permite la transferencia automática de archivos de un PC a otro. Sin embargo, si se cuenta con "Pando", es posible enviarse desde el PC base a cualquier otro en cualquier lugar los archivos deseados. Obviamente para que todo funcione, se requiere que ambos computadores se encuentren prendidos y conectados a la Internet. Otro de los usos frecuentes consiste en poder ayudar a personas que no saben manejar bien los computadores. Al conectarse a través de Logme In, se puede manejar en forma completa el PC remoto, incluso abriendo un archivo de texto, se puede realizar una comunicación interactiva, tipo Chat, entre el notebook y computador remoto que permita explicar como manejar programas, abrir archivos, etc (figura 4).

Aunque lo he mencionado con anterioridad, otro programa muy bueno es Skype (www. skype.com). Permite comunicarse gratuitamente con todos los usuarios conectados en línea y además utilizarlo como sistema de comunicaciones de larga distancia. Para mencionar algunas novedades, se ha incorporado el vídeo como parte estándar, lo que permite realizar videoconferencias de una calidad competitiva a las profesionales, incluso con conexiones de banda ancha de menor velocidad (512 $\mathrm{KB}$ por ejemplo). Se pueden realizar llamadas de larga distancia con un costo de $\$ 10$ el minuto

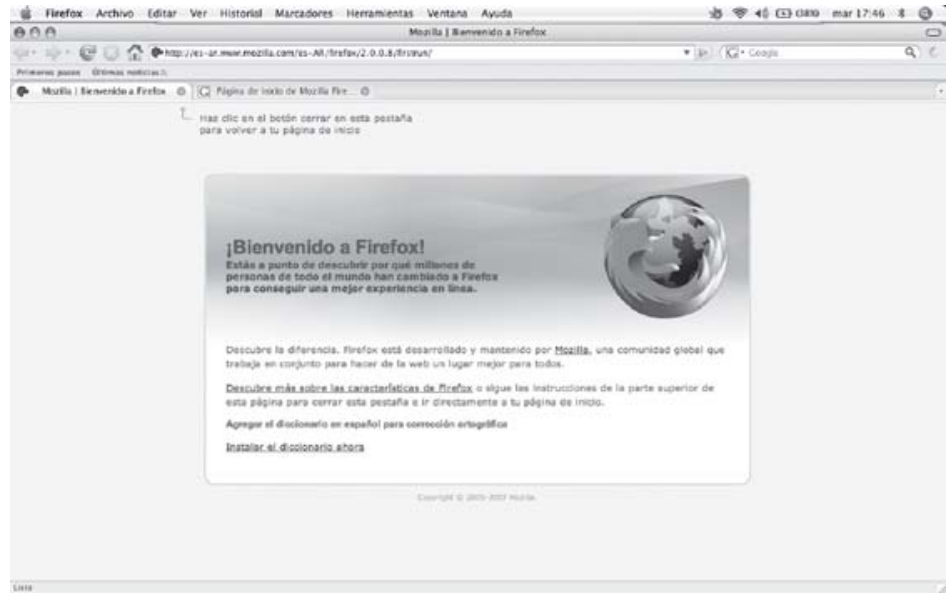

Figura 3.

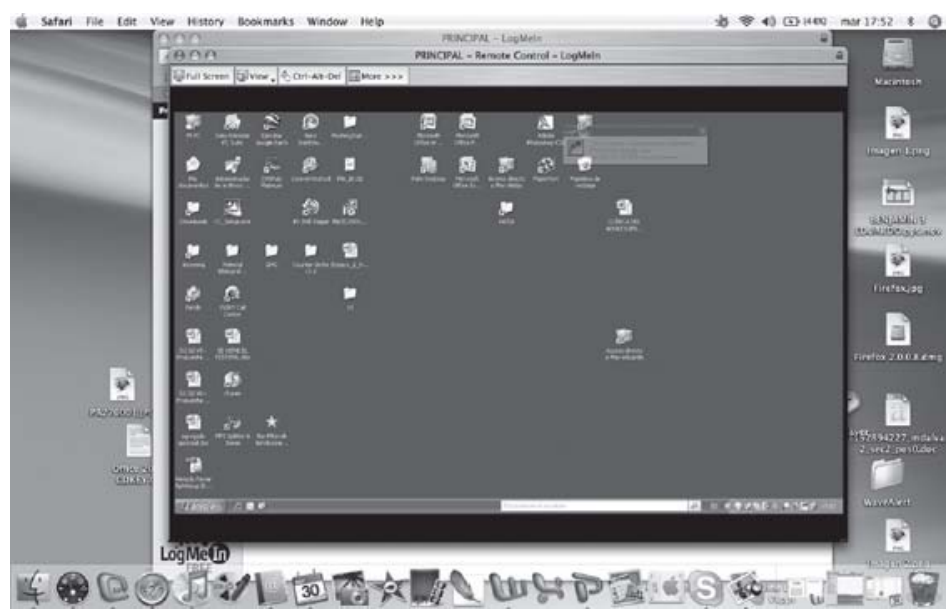

Figura 4.

prácticamente a cualquier parte del mundo, incluyendo la larga distancia nacional en Chile, con una calidad que ha ido mejorando progresivamente. No hay eco y el sonido es excelente. Existe, ahora, un costo adicional de \$10 por establecimiento de llamadas. Las llamadas a los números 800 de Estados Unidos son gratuitas. Existen adaptadores que permiten conectar el los teléfonos corrientes de la casa a Skype y utilizarlo como una línea adicional (www.vosky. com). Incluso se pueden recibir o enviar llamadas de Skype en teléfonos inalámbricos. 